\title{
Pedagogical Approaches to Human Trafficking Through Applied Research Laboratories
}

\author{
Laura A Dean
}

\begin{abstract}
Human trafficking is a phenomenon that lends itself to hands-on pedagogical practices and undergraduate research that, in turn, can create localised knowledge with anti-trafficking stakeholders. Research labs focused on human trafficking are one-on-one or small group applied research settings that build a bridge between the university and anti-trafficking stakeholders over multiple semesters. In this paper, I argue that one way of involving students in the anti-trafficking field is through research laboratories, like the Human Trafficking Research Lab (HTRL). I explore how the HTRL develops pedagogical practices to enable students to work collaboratively with a faculty member and carry out the research process from idea to final draft. Multiple learning outcomes were found, including mentorship, a larger understanding of political science as a discipline, data compilation, presentation and critical thinking skills, and job or graduate school placement. I determined that the HTRL at Millikin offers students hands-on experience with community-engaged projects, including grappling with the ethical implications of knowledge production in social justice advocacy.
\end{abstract}

Keywords: undergraduate research lab, human trafficking, applied research, high impact practices, community stakeholders

Please cite this article as: L A Dean, 'Pedagogical Approaches to Human Trafficking Through Applied Research Laboratories', Anti-Trafficking Review, issue 17, 2021, pp. 56-72, https://doi.org/10.14197/atr.201221174 
Over the past two decades, human trafficking has increasingly become a topic of research interest to students in higher education due to hands-on pedagogical practices through research laboratories. Human trafficking research labs are a broad term for one-on-one or small group applied research projects with or about local stakeholders that bridge university and community settings. Universities are sites of research and innovation, and working with students in these different settings raises important issues of power and knowledge. These issues are particularly salient in the context of human trafficking research because the people most affected by exploitation are often not central to law, policy, or collected knowledge about such experiences. In this paper, I examine the highimpact practices in research laboratories as classes or independent studies for undergraduate students at small to mid-sized universities.

Laboratories for undergraduate research are widespread in the natural sciences and have become more prevalent in the social sciences and humanities. The traditional approach to working with students in social sciences is one-on-one as research assistants or through mentorships with faculty. By contrast, research labs offer an opportunity for résumé building and collaborative research projects in a structured environment while earning course credit over multiple semesters. Additionally, the work with anti-trafficking stakeholders produces benefits for students and universities, fostering connections within the local community that lead to networking opportunities for students and applied research skills, which increase local knowledge on human trafficking and social justice issues. Undergraduate research collaborations that blend teaching and research improve social science and have been found to produce scientific breakthroughs. ${ }^{1}$ Studies indicate a number of ways that designing and implementing undergraduate research produces tangible benefits for students by reinforcing lessons with practical applications, motivating students, ${ }^{2}$ strengthening mentoring relationships, and teaching students about teamwork through listening and compromise. ${ }^{3}$ Research also shows that student research labs produce an increased understanding of complex concepts, problem solving, public speaking skills, and educational outcomes, such as student retention and graduation rates. ${ }^{4}$ This hands-on approach

1 S Herrick, W Matthias and D Nielson, 'How Collaborations with Undergraduates Improve Both Learning and Research: With examples from international development experiments', PS: Political Science \& Politics, vol. 48, issue 1, 2015, pp. 48-52, https:// doi.org/10.1017/S1049096514001590.

2 Ibid.

3 C Elman, D Kapiszewski and D Kirilova, 'Learning Through Research: Using data to train undergraduates in qualitative methods', PS: Political Science \& Politics, vol. 48, issue 1, 2015, pp. 39-43, https://doi.org/10.1017/S1049096514001577.

4 M Becker, 'Importing the Laboratory Model to the Social Sciences: Prospects for improving mentoring of undergraduate researchers', Journal of Political Science Education, vol. 16, issue 2, 2020 pp. 212-224, https://doi.org/10.1080/15512169.2018.1505523. 
allows students to learn the underlying aspects of research processes and reveals the non-linear and sometimes convoluted ways research is conducted in real world social science.

As a global phenomenon, human trafficking is a topic that can be studied with different levels of analysis and governance, focusing on small and large $\mathrm{N}$ studies, and using a variety of methodologies. The salience of human trafficking as a topic also draws in students who are interested in learning more about the complexities of the phenomenon beyond the headlines and movies. It is a topic of cultural significance where students in labs can combat stereotypes and gain hands-on experience researching with local anti-trafficking stakeholders.

In this paper, I reflect on my experience developing an undergraduate research lab, the Human Trafficking Research Lab (HTRL) at Millikin University, which is focused on political science but also includes interdisciplinary themes from gender studies, migration studies, sociology, and criminal justice. First, I describe the varieties of research opportunities and pedagogical approaches offered in different research labs focusing on human trafficking around the world. Then, I discuss how I organised and conducted the HTRL at Millikin and the overall structure that lends itself to undergraduate research. Finally, I examine positionality, ethical implications, and learning outcomes by focusing on the localised implications of trafficking research for students in the lab.

\section{Research Labs in Context}

The concept of research laboratories began in the late nineteenth century as industrial research laboratories or chemical labs in Germany and the United States (US), and then expanded to electrotechnical labs mostly housed in for-profit companies. ${ }^{5}$ After World War II, research labs became an educational learning tool in universities, and only over the past two decades have they expanded from the natural sciences to social sciences and humanities disciplines. With the introduction of service learning and high-impact practices in the twenty-first century, laboratory models have grown across undergraduate education and are used to recruit potential students. Laboratories paid for by the state are an extension of European culture and lauded not only for the research they produce but also for their ability to educate a large number of people on scientific processes and mould future citizens 'to perform effectively (and responsibly) in industrial

5 M de Vries, 'The History of Industrial Research Laboratories as a Resource for Teaching about Science-technology Relationships', Research in Science Education, vol. 31, 2001, pp. 15-28, https://doi.org/10.1023/A:1012610328351. 
economies and mass electoral politics. ${ }^{3}$ Thus, as places of knowledge production, laboratories are inherently political, rooted in for-profit business models, and can reproduce and privilege certain kinds of knowledge, research questions, and methodology over others. The Western roots of this type of learning model and its power dynamics can also perpetuate colonial relations of power that extract knowledge from victims and survivors of human trafficking.? The HTRL and all research labs on human trafficking should cultivate approaches to examining trafficking that uphold practices of equitable access to knowledge and knowledge production and acknowledge the role of universities in perpetuating unequal power dynamics and colonial relations of knowledge production. Students in the HTRL read and engage decolonised research, grapple with the legacies of transatlantic slavery, and work to not perpetuate human trafficking stereotypes. We also try to educate community partners on these stereotypes since community partners can reproduce them by focusing on trafficking for sexual exploitation and only one type of female trafficking victim or racialised ideas of 'white slavery'. In addition, students and professors reflect on how to create transparent relationships with local stakeholders in order to work against the reproduction of an 'us versus them' dichotomy that reifies the ivory tower dynamic.

It is important to consider the power dynamics of research as human trafficking labs are becoming more common. A cursory glance at the most notable labs shows that they range from large interdisciplinary research consortiums to a few professors working on a specific aspect of human trafficking. Social work and criminal justice are the most prevalent disciplines, but other disciplines such as geography, anthropology, sociology, and political science are included in some labs, which reveals the interdisciplinary nature of the topic of human trafficking. Most labs discuss the link between university teaching and learning and the community by providing policy guidance, research support, or other collaborations. One notable research lab on human trafficking is the University of Nottingham's Rights Lab, which has more than eighty scholars. They work with organisations, businesses, and policy partners on their research agenda, focusing on different programme streams such as Data and Measurement, Communities and Society, Ecosystems and the Environment, Law and Policy, and Business and Economies. ${ }^{8}$ Another prominent research lab is the Human Trafficking Center at the University of Denver, which began in 2002 and now consists of ten students and seven faculty, evolving from a task force to a non-profit research and

6 R E Kohler 'Lab History: Reflections', Isis, vol. 99, issue 4, 2008, pp. 761-768, https:// doi.org/10.1086/595769.

7 J Kaye, Responding to Human Trafficking: Dispossession, colonial violence, and resistance among Indigenous and racialized women, University of Toronto Press, Toronto, 2017.

8 'About the Rights Lab', University of Nottingham Rights Lab, 2020, retrieved 28 September 2020, https://www.nottingham.ac.uk/research/beacons-of-excellence/ rights-lab/about/index.aspx. 
advocacy organisation. ${ }^{9}$ Other examples of labs with fewer researchers include the Anti-Slavery and Human Trafficking Initiative at the University of Kansas and the Asian Research Center for Migration at Chulalongkorn University in Bangkok. ${ }^{10}$ The Modern Slavery Research Center at the BRICS Policy Center is a think tank affiliated with the Institute of International Relations of the Pontifícia Universidade Católica do Rio de Janeiro that interrogates the legacy of colonial slavery in Brazil to examine 'place-based anti-slavery strategies [with] local government and law enforcement efforts with voluntary and communitybased actors. ${ }^{11}$ These examples reveal that there are a variety of topics and approaches to human trafficking research based on faculty expertise, funding, and university priorities.

Overall, research labs are a form of experiential learning defined as a 'first-hand experience, active learning, experimentation and adaptation in new environments, and reflection' on the phenomenon being studied. ${ }^{12}$ Research labs differ from research seminars or in-class research projects because they happen over numerous semesters and include a much deeper mentoring experience across the research process, which is not possible in a single semester course. Multiple semesters in the lab allow for participatory action research methods and community engagement. Working with community partners in the lab context means that students consider why research is conducted and what its possible impacts may be. As such, students contemplate the ethical implications and limitations of the laboratory model to challenge power dynamics. Finally, while more labour-intensive, a student-driven (rather than faculty-driven) approach engages students as active partners in research processes. ${ }^{13}$ Most labs in the natural sciences are facultydriven and arranged in a semi-hierarchical structure with weekly meetings or lab interactions that move faculty research forward. ${ }^{14}$ Alternatively, a collaborative

9 'Who We Are', Human Trafficking Center at the University of Denver, 2020, retrieved 28 September 2020, https:// humantraffickingcenter.org/who-we-are.

10 'The ASHTI Story', Anti-Slavery and Human Trafficking Initiative, 2020, retrieved 28 September 2020, https://ipsr.ku.edu/ASHTI; 'Projects', Asian Research Center of Migration, Chulalongkorn University, n.d., retrieved 6 March 2021, http://www. arcmthailand.com/aboutourwork.php.

11 'Modern Slavery Research Center', BRICS Policy Center, n.d., retrieved 6 March 2021, https://bricspolicycenter.org/en/projects/modern-slavery-research-center.

12 J A Moon, Handbook of Reflective and Experiential Learning: Theory andpractice, Routledge, New York, 2004; D A Kolb, Experiential Learning: Experience as the source of learning and development, Prentice Hall, Englewood Cliffs, New Jersey, 1984, as cited in K H Kenyon, 'Bringing the Field into the Classroom: Methods and experiential learning', Politics, vol. 37, issue 1, 2017, pp. 97-112, https://doi.org/10.1177/0263395716633905.

13 K Bauer, 'Early Challenges and Successes from Adapting the Laboratory Model to Undergraduate Teaching Institutions', APS A Preprints, 2020, https://doi. org/10.33774/apsa-2020-lb1rc.

14 Becker. 
student-driven model mobilises student interests and equal engagement in research collaborations. ${ }^{15}$ This is the HTRL model, which is ideal at small liberal arts colleges such as Millikin University.

\section{Design and Structure of Human Trafficking Research Labs}

In the Human Trafficking Research Lab, students work with faculty and learn in a 'community and context where the knowledge is used' and students become members of the lab. ${ }^{16}$ HTRL mentorship is important because even at liberal arts colleges, only a small percentage of students work one-on-one with professors as co-authors on research projects. In the lab, there are formal and informal semistructured mentoring opportunities. While formal mentoring includes meetings and feedback on research, informal mentoring includes spending time in the lab space, doing research in a coffee shop, or taking research assistants to lunch. The lab provides a plethora of opportunities to build different skills. In the beginning, the HTRL was not a physical lab space. Instead, the students and I met in my office at a table with a whiteboard and sketched out our research progress. Due to the visibility of the lab, after a few years we were given a collaborative lab space. Students initially work for course credit, but I also look for ways to fund student research assistants through Millikin's undergraduate research fellows programmes.

Together, we devise a syllabus for independent research that outlines the stages of the research process week by week over the course of multiple semesters. Then we set our assessment (i.e., research goals) for each semester, usually in the form of a final paper or research analysis using conferences or other presentations as benchmarks denoting our progress. Students are expected to be working towards the final research paper but also to update their progress and presentations on the HTRL website in a blog post format at least once a month. ${ }^{17}$ We plan our research project so it can be completed in an academic year and to ensure that students experience all stages of the research process from idea to manuscript. Our research ideas come from working with the Central Illinois Human Trafficking Task Force and community partners who we update on our progress, research impediments, and results. I recruit students for the HTRL from my stand-alone Human Trafficking class, and every research assistant has taken this class during their time at the lab. There are no prerequisites for working in the HTRL; it is open

15 Bauer.

16 T Dahlberg et al., 'Improving Retention and Graduate Recruitment Through Immersive Research Experiences for Undergraduates', ACM SIGCSE Bulletin, vol. 40, issue 1, 2008, pp. 466-470, https://doi.org/10.1145/1352322.1352293.

17 'Research Blog', Human Trafficking Research Lab, n.d., retrieved 6 June 2021, https:// www.humantraffickingresearchlab.org/search/label/Research\%20Blog. 
to anyone interested in the issue of human trafficking and committed to doing a multiple-semester research project. Thus, some research assistants have no prior knowledge of human trafficking and the learning curve is steeper, while others have read extensively on the topic. In the HTRL, we define human trafficking in accordance with the US Trafficking Victims Protection Act (TVPA) of $2000 .{ }^{18}$ We use this definition in our research on laws because most of the cases in our sample are charged under these statutes, but we also discuss the problems with legal definitions and their application, including how anti-trafficking agendas prioritise criminalisation. For instance, in one project on human trafficking task forces, we analysed their over-emphasis on 'sex trafficking' to critically evaluate the US legal definition. In short, although we use 'human trafficking' as an encompassing term, we acknowledge it is a complex and contested issue and we take a critical approach to US legal definitions. This approach is reflected in our research. ${ }^{19}$

The work conducted in the HTRL is done in close connection with the Central Illinois Human Trafficking Task Force and local organisations. We attend meetings and are active players in shaping different task force policies and procedures through the research we conduct. As such, work in the lab often emerges from our engagement with these organisations. For example, after the task force applied unsuccessfully for an Enhanced Collaborative Model Task Force to Combat Human Trafficking grant, a research assistant and I examined different task forces to see what types of task forces are supported with these grants. We gave a presentation to the task force and published a policy brief on our findings that influenced future task force work and how it applied for grants thereafter. At the same time, while our engagement is centred on this task force, students learn about the general anti-trafficking field as well. They also witness the impact of problematic stereotypes, intersections with immigration law, and the consequences of the emphasis on policing. Students relate this first-hand experience to the anti-trafficking literature and deepen their understanding of the relevance and potential impact of research.

18 The TVPA divides human trafficking into two phenomena: sex trafficking as 'the recruitment, harboring, transportation, provision, obtaining, patronizing, or soliciting of a person for the purposes of a commercial sex act, in which the commercial sex act is induced by force, fraud, or coercion, or in which the person induced to perform such an act has not attained 18 years of age' and labour trafficking as 'the recruitment, harboring, transportation, provision, or obtaining of a person for labor or services, through the use of force, fraud, or coercion for the purposes of subjection to involuntary servitude, peonage, debt bondage, or slavery'.

19 See L A Dean and J Sierra, 'Multi-Sector Human Trafficking Task Forces in the United States: Typologies and overlapping jurisdictions', under review. See also other research on our website: 'Research', Human Trafficking Research Lab, n.d., retrieved 6 June 2021, https://www.humantraffickingresearchlab.org/p/research.html. 
The HTRL manual outlines its mission statement, priorities, and values. More recently, a recommended reading list was included to provide students with more background information and contested issues in human trafficking. It includes Siddharth Kara's Sex Trafficking: Inside the business of modern slavery; Jesse Sage and Liora Kasten's Enslaved: True stories of modern day slavery; and Jennifer Musto's Control and Protect: Collaboration, carceral protection, and domestic sex trafficking in the United States. A recent addition to the reading list is Julie Kaye's Responding to Human Trafficking: Dispossession, colonial violence, and resistance among Indigenous and racialized women. This is just a small sample and not an encompassing list of the readings that students engage with when learning about the topics. I highlight these texts because they are approachable for an undergraduate audience delving into the human trafficking literature and students have noted that these texts are among their favourites on the reading list.

The HTRL promotes a performance learning approach in dialogue with the critical service-learning literature that 're-imagines the roles of community members, students, and faculty in the service-learning experience ... to deconstruct systems of power so the need for service and the inequalities that create and sustain them are dismantled. ${ }^{20}$ This approach is especially important because the root causes of human trafficking are complex. The research in the HTRL aims to address inequities, including the exercise of care and making an impact beyond the research while paying attention to concerns about involving 'students in the community in a way that perpetuates inequality and reinforces an "us-them" dichotomy. ${ }^{21}$ Students take the lessons they have learned through their research and actively engage in critical thinking concerning task force members and their role in the anti-trafficking apparatus. For example, students have noted the questionable views of some police members when discussing sting operations and the carceral approach to human trafficking. Problematic terminology and power dynamics related to 'rescue' and 'saving' victims is another issue we have raised with the task force, such as when a member of Immigration and Customs Enforcement wanted all trafficking victims to be vetted by their office. One of my students told the task force about how that approach could be harmful for foreign-born trafficked persons with unclear immigration statuses. Students have also noted the growth of organisations working on human trafficking in our region and the singular focus of some organisations that only rehabilitate certain victims. These examples demonstrate how students take the critical approach from the lab and apply it to our interactions with community partners. This balance can be delicate because students learn to weigh this critical lens and constructive feedback with the possibility of alienating local partners.

20 T D Mitchell, 'Traditional vs. Critical Service-Learning: Engaging the literature to differentiate two models', Michigan Journal of Community Service Learning, Spring 2008, pp. 50-65.

$21 \quad$ Ibid., p. 51. 
The performance learning approach with third-party stakeholders, i.e., local partners, leads to critical perspectives about the task force as students are often surprised at the lack of human trafficking knowledge possessed by some task force members, as well as the critical perspectives mentioned previously. In our research on task forces, we highlight how anti-trafficking approaches perpetuate inequality by focusing on female victims of trafficking in the sex industry. We share our research findings and criticisms with the task force because one way to combat these stereotypes is to confront how the task force and member organisations can perpetuate them. Our task force research includes Indigenous- and Native-centred task forces, often left out of existing research on anti-trafficking task forces in the US. In our adjudication research project, we are examining the race and gender of people arrested for trafficking crimes, demonstrating different concepts of intersectionality in how these crimes are charged in the US. Acknowledging and not reproducing stereotypes in research and interactions with the antitrafficking community are a necessary component of research labs on human trafficking: it should embrace a service-learning approach that 'emphasize[s] the skills, knowledge, and experiences required of students to not only participate in communities, but to transform them as engaged and active citizens. ${ }^{.22}$ The research we presented did not avoid criticisms and offered opportunities to improve anti-trafficking advocacy. Most community members welcomed the feedback. Overall, we allow for disagreements, and there are research approaches from the lab that task force members do not support, but thus far disagreements have been handled respectfully.

\section{Research Lab Operation}

I have experimented with different ways to include students in research through the operation of the lab. I offer a stand-alone Human Trafficking class and integrated pre-tests as assignments for students that influence a longer research project. I found that my class on human trafficking is a great testing ground to determine if research ideas are worth investigating further. For example, I assigned a paper on human trafficking task forces in the United States that asked students to conduct background research and analysis on one task force. I took this preliminary information and used it as the basis for a paper with a student from the class under the auspices of the HTRL. We were able to obtain summer funding for the student who then registered for an independent study with the HTRL during the academic year to complete the research and write up the results. We examined and mapped more than 200 task forces throughout all 50 states and Puerto Rico and outlined the origin, scope, and variation of this anti-trafficking institution in the US. ${ }^{23}$

22 Ibid., p. 52.

23 Dean and Sierra. 
Moreover, I have used my Political Science Research Methods course as an opportunity for undergraduate research with the HTRL. As a small class of 12 students, we conducted research on human trafficking cases in Illinois, tracking human trafficking charges and their outcomes. Collaboratively, I taught students how to conduct research with the hands-on approach from the HTRL by actually doing the research. We began thinking about research questions, compiled and tracked court cases in numerous Illinois counties, and analysed results. I then chose one student from the class to work in the HTRL the next semester, continuing the work by finalising data collection and the literature review. We will present findings at the poster session at the Day of Scholarship and hope to publish the final article in a peer-reviewed journal. Since this work was done during the COVID-19 pandemic, presenting at an academic conference with students was unlikely, but it would normally be an option and professional development opportunity for the students.

Another rendition of collaborative undergraduate research experience is the traditional one-on-one model where students conduct an independent study with me and work on a designated research project. To plan the development of the project, we outline the goals and assignments for every week during the summer or semester and recalibrate the outline if tasks take longer than estimated or other external factors impede research progress. Students in the lab provide peer reviews on drafts to each other, which lends another level of feedback and engagement with the literature. Though much of the research work is autonomous and conducted physically outside of the HTRL, students still receive a significant amount of time and accountability on the project with a research professional in the field. Table 1 outlines the basic HTRL tasks list that shows the short-term and long-term tasks for student research assistants. 


\section{Table 1: Human Trafficking Research Lab Tasks List}

\begin{tabular}{|l|l|l|}
\hline \multicolumn{1}{|c|}{ Task } & \multicolumn{1}{c|}{ Description } & \multicolumn{1}{c|}{ Outcomes } \\
\hline $\begin{array}{l}\text { Complete an } \\
\text { annotated } \\
\text { bibliography } \\
\text { entry for our } \\
\text { study }\end{array}$ & $\begin{array}{l}\text { Using Google Scholar, find articles that we } \\
\text { have not yet cited but could be relevant to our } \\
\text { current research study. Then read and write-up an } \\
\text { annotation with key ideas that are linked to our } \\
\text { research project and a full citation. }\end{array}$ & Annotated bibliography \\
\hline $\begin{array}{l}\text { Write a blog } \\
\text { post on your } \\
\text { work or a recent } \\
\text { article related } \\
\text { to human } \\
\text { trafficking }\end{array}$ & $\begin{array}{l}\text { You are required to post at least one update a } \\
\text { month on the Human Trafficking Research Lab } \\
\text { blog (https://wwwhumantraffickingresearchlab. } \\
\text { org). If you have extra time during your week } \\
\text { you could write an additional post on your work } \\
\text { or respond to an article that you read on human } \\
\text { trafficking. }\end{array}$ & Completed blog post \\
\hline $\begin{array}{l}\text { Write an SSN } \\
\text { research brief }\end{array}$ & $\begin{array}{l}\text { Write a research brief for one of my published } \\
\text { articles on the Scholars Strategy Network (SSN). }\end{array}$ & SSN research brief \\
\hline
\end{tabular}

\section{Long-Term tasks (Ongoing throughout the semester)}

\begin{tabular}{|l|l|l|}
\hline \multicolumn{1}{|c|}{ Task } & \multicolumn{1}{c|}{ Description } & \multicolumn{1}{c|}{ Outcomes } \\
\hline $\begin{array}{l}\text { Data } \\
\text { compilation }\end{array}$ & $\begin{array}{l}\text { Enter case data on arrests and charges into our } \\
\text { database on the Google Docs folder. Then code the } \\
\text { cases according to our predetermined coding scheme. } \\
\text { Highlight the new cases that you add so I can double- } \\
\text { check them. }\end{array}$ & Research update \\
\hline $\begin{array}{l}\text { Fix } \\
\text { bibliographic } \\
\text { citations to } \\
\text { match the } \\
\text { journal style }\end{array}$ & $\begin{array}{l}\text { Aligning citations to journal style is a required task for } \\
\text { many researchers and many times citations need to be } \\
\text { reformatted to fit a different journal. Your task is to } \\
\text { change the sources to fit the journal style. }\end{array}$ & $\begin{array}{l}\text { Input citations in the } \\
\text { draft of our manuscript }\end{array}$ \\
\hline $\begin{array}{l}\text { Send an email } \\
\text { or stop by } \\
\text { my office and } \\
\text { ask for other } \\
\text { research tasks }\end{array}$ & $\begin{array}{l}\text { There are always many research tasks to complete, } \\
\text { including finding literature, proofreading, reference } \\
\text { checking, or formatting. If you run out of tasks to } \\
\text { complete for the week let me know and I can send } \\
\text { you some other research tasks. }\end{array}$ & $\begin{array}{l}\text { Submit your work on a } \\
\text { task-by-task basis }\end{array}$ \\
\hline
\end{tabular}

Note: The Human Trafficking Research Lab Tasks List is used with students in the lab if they have finished their weekly tasks and have extra time during a given week to perform additional research duties. Adapted from colleagues Amy Delaney $^{24}$ and Rebecca Kreitzer.

24 A L Delaney and G Singleton, 'Information and Relationship Functions of Communication Between Pregnant Women and Their Health Care Providers', Communication Studies, vol. 71, issue 5, 2020, pp. 800-822, https://doi.org/10.1080/1 0510974.2020.1807376. 
We have weekly lab meetings during the semester to discuss research progress and impediments. These discussions create a community of learners, and even though students might be working on different projects, they bring questions and problems to the entire group, and we work through them together. In meetings, we outline common goals for the week, facilitate group discussion to move research forward, and synthesise ideas to advance the knowledge about human trafficking. We also choose research questions and topics that are approachable for undergraduate students, which influences the research we undertake. We try to focus on more local research projects that build knowledge and present it to the task force, which is a good sounding board for our findings. This collaboration builds confidence and connects student research to the efforts of task force members working in our local community. We always formulate a one- to two-page research brief and circulate it to the task force, which can also help organisations with grants or donors and shows the impact of the HTRL, as part of the task force's work in our community.

Presenting to local anti-trafficking stakeholders helps students practise giving professional presentations and demonstrates the value of research for local antitrafficking advocacy. Moreover, having students as research assistants influences the potential impact of our research as some community members are more willing to answer challenging questions posed by students. Given that most task force members do not read academic research on human trafficking, our research has the potential to bridge scholarly and policy communities. The lab produces knowledge through academic presentations and publications, it builds knowledge on campus and in our community through our annual human trafficking awareness month talk, and educates the task force by sharing our ideas and research related to local anti-trafficking efforts.

\section{Educational Challenges and Tensions}

The work at the HTRL is not without its challenges and tensions. The competition for grants both in and outside of the university to fund the lab employs a neoliberal ideology where the lab is seen as an entrepreneurial entity that can maximise human capital to benefit the university. ${ }^{25}$ This dichotomy creates tensions as universities might seek to gain from housing research labs on human trafficking. There are also tensions from government-funded projects and other funding agencies that might have strings attached to grant opportunities that clash with the research lab's mission. Additionally, internal funding opportunities for research

25 E M Vazquez and J S Levin, 'The Tyranny of Neoliberalism in the American Academic Profession', American Association of University Professors, January-February 2018, retrieved 29 April 2021, https://www.aaup.org/article/tyranny-neoliberalismamerican-academic-profession\#.YIq2M7VKhPY. 
assistants are competitive and can create tensions among the different research labs within the university as more social science and humanities-based labs compete with the natural sciences for a finite set of resources.

Within this context, the positionality of a researcher is an important component to research labs focused on human trafficking. In the lab, we promote an intersectional and victim-centred perspective that seeks to decolonise human trafficking research by acknowledging the legacies of slavery and exploitation in the US. We enact this positionality in the ways that we approach our projects, such as including Indigenous-led groups in our task force paper and examining the adjudication of trafficking cases where we determined that some cases were charged with lower statutes and ended in plea deals. Additionally, we critique the rescue mentality and the racialised approach to 'rescue' operations focused on white women when the data show that trafficked persons in the US are disproportionately people of colour. ${ }^{26}$

At the same time, my status as an educated white woman affiliated with an academic institution affords privileges and access to spaces and conversations with community partners. While students come from more diverse backgrounds, most of the anti-trafficking stakeholders we interact with are white, which means many times the students are among a handful of people in the room from historically excluded communities. There are also tensions and dynamics with community partners who might not agree with our intersectional research methods. The community partners in social services are mostly white women and the police and states attorneys are mostly white men. Gender, race, and class differences among the students influence how we navigate community relationships. Likewise, my positionality affects the mentor/mentee relationships because there is always a power dynamic, especially if the student takes the lab as a class for a grade. Most of the research assistants are political science students so seeking paid opportunities in the lab also produces an employer/ employee relationship. Research assistants have diverse backgrounds that lend perspectives on the dynamics with community partners and inform aspects of the research. For example, some students have fraught relationships with the US immigration regime's treatment of undocumented or refugee relatives because some immigration policies may actually facilitate, rather than prevent, trafficking. Students from racially marginalised groups have added perspectives on the problematic racial dimensions of trafficking charges in our adjudication research. Being in a university-based research lab allows us to research topics of interest to us and this position influences how the research is conducted and the social contexts that inform it. All participants in human trafficking research

26 'Racial Disparities, COVID-19, and Human Trafficking', Polaris Project, 29 July 2020, retrieved 29 April 2021, https://polarisproject.org/blog/2020/07/racial-disparitiescovid-19-and-human-trafficking. 
labs need to think about their place in the community and cultivate critical engagement given their positions and the tensions that are a part of conducting community-based research.

For students, one challenge is how to cope with midterm and final exams as well as other commitments (e.g., family, work, education costs, mental health) while conducting research at the lab. This is why I allow them to take a week off and make up their hours. The feedback in lab meetings helps to manage students' research expectations and gives them time to reformulate work that did not meet course expectations. Students have the freedom to make mistakes and fix them because we work on projects for an extended period. Although we initiate research ourselves, labs that include work with clients, survivors, or victims should balance distressing human trafficking topics and consider if they are appropriate for students. Lab directors need to be cognisant of the limits of research projects with students, especially undergraduates, and how research can trigger student experiences with trauma. Students in the lab are allowed mental health days and campus mental health resources are listed in the lab manual and are available for students working with difficult topics or situations.

Tensions can also arise between the lab and community organisations that are members of the research subcommittee because they may have different goals than the research lab; for example, members have advocated against including certain variables (e.g., gender and race) in task force survey design. However, the lab has been a member of the task force almost since its establishment and tensions have been rare. Including community partners in the research and reporting of our research progress helps stave off the ivory tower dynamic where researchers parachute in to obtain data and leave just as abruptly. Instead, task force members view our lab as an accessible partner, which mitigates tensions.

Another challenge of research labs are the ethical implications of having students doing unpaid academic research where they pay tuition to obtain course credit. This dynamic could be considered exploitative. These types of quandaries are important to think about when establishing a research lab on human trafficking because researchers need to create working conditions that do not exploit students. As researchers and teachers, we need to focus on ways to ensure students are compensated for their work and to delineate the educational and professional benefits to lab work. The research experience coupled with mentoring and assistance with job placement or graduate school recommendations offers several benefits for students. However, seeking out other funding opportunities for students when available is an important way to show the value of student research and keep exploitative labour practices to a minimum. 
Finally, there are myriad of ethical issues when research includes victims and survivors of human trafficking. In addition to robust and ongoing conversations about ethical research practices, students are trained (and certified) through the university's Institutional Review Board. While it is impossible to 'do no harm', we engage practices that avoid re-traumatisation and are trauma-informed. ${ }^{27}$ This ethical commitment means seeking out and listening to community members' needs. It is vital not to perpetuate stereotypes and incorrect data on human trafficking and to not tokenise survivor perspectives. Sometimes, this commitment entails educating local stakeholders on problematic statistics or their singular focus on certain trafficking victims.

\section{Learning Outcomes}

Student research assistants gain practical skills in the HTRL and have demonstrated increased educational ownership by working in the lab. One student wrote on our research blog, 'Through this research lab, I have been exposed to better researching techniques and my research has improved'. ${ }^{28}$ First, students gain a greater understanding of political science as a discipline and they are able to assess research and data published in academic papers, as well as in the local media and by think tanks with an anti-trafficking lens. By organising and tracking human trafficking data, students learn data compilation and dataset management skills, which some mention as one of the most useful skills obtained in the lab. They learn how to analyse this data through statistical investigation or content analysis and coding, and by conveying the findings to both academic and non-academic audiences. These data management and analysis skills facilitate professionalisation, time management, and project management that can help in students' future career.

Second, the lab teaches students survey question development and data compilation as the HTRL sends surveys to different agencies to collect data on human trafficking trainings. Students have learnt how to create data visualisations that bring the lab's research to fruition in basic graphs and tables in Excel and in mapping software such as Tableau. A student commented on our research blog that 'one of the many skills I have been able to gain and strengthen through my position on the [HTRL] is my spreadsheet creation and maintenance on programs

27 R Surtees and A Brunovskis, 'Doing No Harm —Ethical challenges in research with trafficked persons', in D Siegel and R de Wildt (eds.), Ethical Concerns in Research on Human Trafficking, Studies of Organized Crime, vol. 13, Springer, Cham, 2016, pp. 137-154, https://doi.org/10.1007/978-3-319-21521-1_9.

28 'Working On The Lit Dump', Human Trafficking Research Lab, 16 February 2019, retrieved 12 March 2021, https://www.humantraffickingresearchlab.org/2019/02/ working-on-lit-dump.html. 
such as Google Sheets and Microsoft Excel'. ${ }^{29}$ Third, the HTRL fosters increased understanding of complex concepts and problem-solving skills as we study a phenomenon that is not always clear and locate hidden data to uncover more about different human trafficking dynamics.

Due to the number of presentation opportunities in the lab, students develop public speaking skills and learn to present complex information to the public. One student wrote after presenting at our poster symposium, 'I felt as if I was extremely prepared despite not having any notecards to rely on because of the numerous presentations given before the poster symposium ... Most of the people I explained our research to were unaware of the countrywide efforts of the United States government and I was proud to be able to provide them with that information. ${ }^{30}$ This comment attests to how the HTRL builds knowledge on human trafficking in our community through the skills that students gain. Working in the lab cultivates collaboration skills even with students who dislike group projects. When working on joint research projects, students pull their weight and do the assigned research. Even in the larger class applications of the lab, students see the assignments as having a 'real-world' impact that motivates them to produce quality projects. Students who have graduated now work in a variety of industries, including migrant rights organisations. Working as a research assistant in the HTRL is not just a line on a résumé because the lab builds many applicable skills and learning outcomes that are hard to replicate in other classroom-based educational experiences.

\section{Conclusion}

The HTRL at Millikin University gives students the opportunity to work collaboratively with a faculty member and carry out the research process from idea to final draft. In this paper, I discussed three different research approaches using the HTRL as a pre-test trial for larger research ideas; as a part of a research methods class to showcase hands-on research from idea to full paper draft; and as a one-on-one collaborative research model with select students working on different themes related to human trafficking. Several learning outcomes were found including mentorship, a larger understanding of political science as a discipline, data compilation, presentation and critical thinking skills, and job or graduate school placement. Though there are ethical implications involved in human trafficking research labs that researchers must keep in mind, for the most

29 'Sheets Experience', Human Trafficking Research Lab, 16 March 2019, https:/ /www. humantraffickingresearchlab.org/2019/03/sheets-experience.html.

30 'Winning Third Place at Millikin's 2019 Celebration of Scholarship Poster Symposium', Human Trafficking Research Lab, 1 May 2019, retrieved 12 March 2021, https:/ /www. humantraffickingresearchlab.org/2019/06/winning-third-place-at-millikins-2019.html. 
part, labs offer students hands-on experience with community-informed projects that build knowledge and social justice work with implications beyond academia.

Human trafficking research labs conducting research with stakeholders are a valuable pedagogical tool for undergraduate research. Due to the shared local knowledge of anti-trafficking stakeholders, students gain hands-on experience with the complexities of human trafficking through high-impact educational practices. Interactions between students in the lab and local community members have the potential to contribute diverse voices to the anti-trafficking field and produce innovative scholarship that challenges the status quo. Research labs are effective models for the hard sciences but applying them to complex topics in the social sciences and humanities takes adaptation and attention. Undergraduate students require more hands-on communication, interactions, and training than similar research lab models in think tanks and research clusters made for researchers with advanced degrees. Student-driven models promoting students as research partners are the most equitable approach when working with complex topics, but they are also time-consuming and labour-intensive endeavours, especially for faculty with heavy teaching loads. Future research could take this case study further and examine the comparative impacts of student-faculty collaborative research labs focused on human trafficking around the world. The ethical implications raised could be explored further as bigger labs with larger government and private funding streams likely encounter more tensions balancing ethical research and teaching. Overall, I found that human trafficking research labs disseminate knowledge and combat stereotypes that increase knowledge on human trafficking dynamics and characteristics in the local community.

Laura A Dean is an Associate Professor of Political Science and Director of the Human Trafficking Research Lab at Millikin University. She researches gender and politics issues focusing on public policy, migration, and gender-based violence in Eurasia. She is the author of Diffusing Human Trafficking Policy in Eurasia (Policy Press, University of Bristol) which examines the adoption and implementation of human trafficking policy and the resulting institutions and networks. Email: deanla12@gmail.com 